\title{
Analysis of cardiopulmonary stress during endoscopy: Is unsedated transnasal esophagogastroduodenoscopy appropriate for elderly patients?
}

\author{
Kazuhiko Uchiyama MD PhD¹, Takeshi Ishikawa MD PhD¹, Naoyuki Sakamoto MD PhD , Hirokazu Kajikawa MD PhD², \\ Tomohisa Takagi MD PhD¹, Osamu Handa MD PhD¹, Yoshihide Tatsumi MD PhD ${ }^{3}$, Nobuaki Yagi MD PhD', \\ Yuji Naito MD PhD', Yoshito Itoh MD PhD¹, Shuhei Takemura MD PhD²
}

\begin{abstract}
K Uchiyama, T Ishikawa, N Sakamoto, et al. Analysis of cardiopulmonary stress during endoscopy: Is unsedated transnasal esophagogastroduodenoscopy appropriate for elderly patients? Can J Gastroenterol Hepatol 2014;28(1):31-34.
\end{abstract}

BACKGROUND: Transnasal esophagogastroduodenoscopy (EGD) without sedation has been reported to be safe and tolerable. It has recently been used widely in Japan for the detection of upper gastrointestinal disease. Alternatively, transoral examination using a thin endoscope has also been reported to be highly tolerable.

OBJECTIVE: To examine the cardiocirculatory effects of transoral versus transnasal EGD in an attempt to determine the most suitable endoscopic methods for patients $\geq 75$ years of age.

METHODS: Subjects who underwent monitoring of respiratory and circulatory dynamics without sedation during endoscopic screening examinations were enrolled at the New Ooe Hospital (Kyoto, Japan) between April 2008 and March 2009. A total of 165 patients (age $\geq 75$ years) provided written informed consent and were investigated in the present study. Patients were randomly divided into three subgroups: UO group - thin endoscope; SO group - standard endoscope; and UT group - transnasal EGD. Percutaneous arterial blood oxygen saturation, heart rate and blood pressure were evaluated just before EGD and at five time points during EGD. After transnasal EGD, patients who had previously been examined using transoral EGD with a standard endoscope were asked about preferences for their next examination.

RESULTS: There were no statistical differences in the characteristics among the groups. Percutaneous oxygen saturation in the UT group showed a transient drop compared with the $\mathrm{SO}$ and $\mathrm{UO}$ groups at the beginning of the endoscopic procedure. Heart rate showed no significant differences among the SO, UO and UT groups; Systolic blood pressure in the UO group was lower immediately after insertion compared with the SO and UT groups. The rate pressure product in the UO group was comparable with that in the UT group during endoscopy, and the SO group showed a continuously higher level than the UO and UT groups. More than one-half (54.4\%) of patients were 'willing to choose transnasal EGD for next examination'.

CONCLUSIONS: For elderly patients, unsedated transnasal EGD failed to show an advantage over unsedated standard endoscopy. Transoral thin EGD was estimated to be safe and tolerable.

Key Words: Cardiocirculatory effects; Elderly patients; Transnasal esophagogastroduodenoscopy

- sophagogastroduodenoscopy (EGD) is widely used in Japan for the Edetection of upper gastrointestinal disease. However, the utility of sedation and the appropriate types of endoscope and methods remain unclear. Elderly patients generally have a higher risk of complications in EGD, including complications from sedation. Although the use of
L'analyse du stress cardiopulmonaire pendant

l'endoscopie : l'œsophago-gastro-duodénoscopie transnasale sans sédation convient-elle aux patients âgés?

HISTORIQUE : L'œsophago-gastro-duodénoscopie (OGD) transnasale sans sédation est considérée comme sécuritaire et tolérable. Elle a récemment été largement utilisée au Japon pour déceler une maladie de la partie supérieure du système digestif. De même, l'examen transoral à l'aide d'un endoscope mince est considéré comme très tolérable.

OBJECTIF : Examiner les effets cardiocirculatoires de l'OGD transorale par rapport à l'OGD transnasale dans une tentative pour déterminer la méthode endoscopique la mieux adaptée aux patients de 75 ans et plus.

MÉTHODOLOGIE : Des sujets qui avaient subi une surveillance de leur dynamique respiratoire et circulatoire sans sédation pendant un dépistage endoscopique ont été enrôlés dans à l'étude menée à l'hôpital New Ooe de Kyoto, au Japon, entre avril 2008 et mars 2009. Au total, 165 patients (de 75 ans ou plus) ont fourni un consentement éclairé écrit et participé à l'étude. Les patients ont été répartis au hasard en trois sous-groupes : groupe UO - endoscope mince, groupe $\mathrm{SO}$ - endoscope standard et groupe UT - OGD transnasale. Les chercheurs ont évalué leur saturométrie percutanée, leur fréquence cardiaque et leur tension artérielle juste avant l'OGD et à cinq moments pendant l'OGD. Après l'OGD transnasale, les patients qui avaient été examinés auparavant au moyen d'une OGD transorale par endoscope standard ont été invités à préciser leurs préférences pour l'examen suivant.

RÉSULTATS : Il n'y avait pas de différences statistiques quant aux caractéristiques des groupes. La saturométrie percutanée du groupe UT a révélé une baisse transitoire par rapport aux groupes $\mathrm{SO}$ et $\mathrm{UO}$ au début de l'intervention endoscopique. La fréquence cardiaque ne présentait pas de différence significative entre les groupes SO, UO et UT. La tension artérielle systolique du groupe UO était plus basse que celle des groupes SO et UT immédiatement après l'insertion. Le produit de pression du groupe UO était comparable à celui du groupe UT pendant l'endoscopie, et le groupe SO a présenté un taux constamment plus élevé que les groupes UO et UT. Plus de la moitié $(54,4 \%)$ des patients étaient « prêts à choisir l'OGD transnasale à l'examen suivant ». CONCLUSIONS : Chez les patients âgés, l'OGD transnasale sans sédation n'était pas plus avantageuse que l'endoscopie standard sans sédation. L'OGD transorale à l'aide d'un endoscope mince était considérée comme sécuritaire et tolérable.

sedation during EGD has been shown to increase patient tolerance, and prevent increases in systolic blood pressure and heart rate $(1,2)$, various adverse side effects, such as hypoxia, have been reported with sedation $(3,4)$. Transnasal EGD has been reported to be safe without sedation $(5,6)$. It is associated with decreased cardiopulmonary stress

${ }^{1}$ Molecular Gastroenterology and Hepatology, Kyoto Prefectural University of Medicine; ${ }^{2}$ New Ooe Hospital, Kyoto; ${ }^{3}$ Department of Gastrointestinal Diseases, Panasonic Health Care Center, Osaka, Japan

Correspondence and reprints: Dr Kazuhiko Uchiyama, Molecular Gastroenterology and Hepatology, Kyoto Prefectural University of Medicine, 465 Kajiicho

Hirokoji Kawaramachi Kamigyo-ku, Kyoto, Japan 602-8566. Telephone 81-75-251-5518, fax 81-75-251-0710, e-mail k-uchi@koto.kpu-m.ac.jp

Received for publication August 27, 2013. Accepted September 19, 2013 
TABLE 1

Patient characteristics and baseline cardiopulmonary parameters in the study groups

\begin{tabular}{|c|c|c|c|c|}
\hline Characteristic & $\begin{array}{c}\text { SO } \\
(n=55)\end{array}$ & $\begin{array}{c}\text { UO } \\
(n=53)\end{array}$ & $\begin{array}{c}\text { UT } \\
(n=57)\end{array}$ & $\mathbf{P}$ \\
\hline Age, years, mean $\pm S D$ & $80.1 \pm 4.7$ & $80.2 \pm 4.3$ & $80.6 \pm 3.8$ & NS \\
\hline Sex, male/female, $n / n$ & $30 / 25$ & $25 / 28$ & $31 / 26$ & NS \\
\hline $\begin{array}{l}\text { Percutaneus oxygen } \\
\text { saturation, } \%\end{array}$ & $97.1 \pm 2.5$ & $97.5 \pm 1.8$ & $97.1 \pm 3.2$ & NS \\
\hline Heart rate, beats/min & $70.1 \pm 13.3$ & $71.8 \pm 13.3$ & $73.2 \pm 14.0$ & NS \\
\hline $\begin{array}{l}\text { Systolic blood pressure, } \\
\text { mmHg }\end{array}$ & $139.6 \pm 23.0$ & $137.2 \pm 13.1$ & $135.7 \pm 15.4$ & NS \\
\hline Procedure time, $\min$ & $6.09 \pm 0.28$ & $5.12 \pm 0.28$ & $6.30 \pm 0.40$ & NS \\
\hline
\end{tabular}

Data presented as mean $\pm S D$ unless otherwise indicated. SO group - transoral standard endoscope (GIF-XQ260; Olympus, Japan); UO group - transoral thin endoscope (GIF-XP260; Olympus); UT group-transnasal endoscope (GIF-XP260N; Olympus). NS Not statistically significant

during EGD (7). Unsedated transnasal EGD has also been reported to show a similar rate of tolerability compared with transoral EGD under conscious sedation (8-13). Although endoscopy in elderly patients is being performed with increasing frequency in Japan, we have little information regarding the relative safety of transnasal and transoral EGD in these patient groups. Transnasal EGD has been reported to be safer than transoral EGD for elderly patients (14). On the other hand, transoral thin EGD has been also reported to be safe and tolerable compared with standard EGD $(15,16)$. Elderly patients do not frequently gag or choke during transoral EGD. If transoral EGD is safe and comfortable for elderly patients, the value of transnasal EGD for elderly patients may be limited. The comparative safety and acceptability of the two techniques should, therefore, be considered carefully in the treatment of elderly patients with higher risks for gastric cancer and cardiopulmonary diseases. We compared the safety and tolerability of transnasal and transoral EGD in patients $\geq 75$ years of age. We prospectively compared and evaluated changes in hemodynamic and pulmonary function during each method of EGD.

\section{METHODS}

\section{Study population}

The study population comprised patients who underwent monitoring of respiratory and circulatory dynamics during endoscopic screening examinations without sedation at the New Ooe Hospital (Kyoto, Japan) between April 2008 and March 2009. It was determined that a standard effect size of 0.6 would be a clinically significant difference in the numerical data; it was estimated that a sample size of 46 patients per group would be required to detect this difference with $80 \%$ power at a 5\% significance level. A total of 165 patients (age $\geq 75$ years) provided written informed consent and were investigated in the present study. Patients were excluded from the study if they opted to receive sedation, had a history of undergoing sedated endoscopy or of psychiatric disease, were currently receiving anticoagulation therapy, if a therapeutic procedure was considered likely to be required or if a bleeding diathesis was identified. Patients with cardiac disease, pulmonary disease or psychological disease, and who had undergone partial or total gastrectomy were also excluded from the study. The present study was approved by the Institutional Review Board of the New Ooe Hospital. Data analyses conformed with the principles of the Declaration of Helsinki (17).

\section{Endoscopic equipment}

After providing written informed consent, patients were randomly assigned using the sealed envelope method to three subgroups: SO group - transoral standard endoscope (GIF-XQ260; Olympus, Japan); UO group - transoral thin endoscope (GIF-XP260; Olympus); and UT group - transnasal endoscope (GIF-XP260N; Olympus).
The diameter of the inserted portion of the endoscope was $6.5 \mathrm{~mm}$ for the GIF-XP260, $9.0 \mathrm{~mm}$ for the GIF-XQ260 and $5.0 \mathrm{~mm}$ for GIFXP260N. All procedures were performed by three senior endoscopists with $>15$ years of experience each. Only topical anesthesia was used, with no sedative agents. All patients were administered antispasmodic medications $5 \mathrm{~min}$ before the examination.

Patients in the $\mathrm{UO}$ and $\mathrm{SO}$ groups received only local throat anesthesia with $4 \mathrm{~mL}$ of $2 \%$ viscous lidocaine (Xylocaine, AstraZeneca, Japan) for $5 \mathrm{~min}$. Patients in the UT group received local anesthesia in the form of a nasal spray consisting of $0.5 \%$ phenylephrine and $2 \%$ Xylocaine, delivered as a fine mist using a mucosal atomization device (Wolfe Tory Medical, USA) attached to a $10 \mathrm{~mL}$ syringe, and cetacaine spray for pharyngeal anesthesia.

\section{Monitoring of respiratory/circulatory hemodynamics}

Duration of the examination, percutaneous arterial blood oxygen saturation and heart rate were measured at the right first finger, and blood pressure was measured at the upper right arm using a monitoring unit (MUE-200, Olympus). These parameters were evaluated at six timepoints ( 2 min before the examination; at four time points during insertion of the endoscope [esophagus, gastric angle to antrum, pyloric ring to the duodenal bulb and upper gastric body]; and immediately after evulsion of endoscope), then compared among groups. Blood pressure was measured according to a previous report (18). In addition, ratepressure product (pulse rate $\times$ systolic blood pressure/100) reportedly offers a useful marker of cardiac oxygen demand and was, therefore, calculated $(19,20)$.

\section{Questionnaire survey}

After transnasal EGD had been performed, the patients, who had all previously been examined by transoral EGD using a conventional endoscope, were asked about their preferences regarding a subsequent upper gastrointestinal examination. Patients were able to select one of three options: would prefer transnasal EGD; no preference for transnasal or transoral EGD; or would prefer transoral EGD.

\section{Statistical analysis}

For statistical analysis, Statview statistical software (SAS Institute, USA) was used. Data are expressed as the mean \pm SD. The MannWhitney $U$ test and Wilcoxon's rank-sum tests were used; $\mathrm{P}<0.05$ was considered to be statistically significant.

\section{Patient characteristics}

\section{RESULTS}

All patients enrolled in the study were analyzed. Characteristics of the enrolled patients in each group are summarized in Table 1. No serious complications in cardiopulmonary function occurred. There were no statistically significant differences in mean age, baseline cardiopulmonary parameters, arterial oxygen saturation, heart rate or systolic blood pressure among the groups.

Duration of endoscopic procedure

The mean $( \pm \mathrm{SD})$ duration of the endoscopic procedure was $6.09 \pm 0.28 \mathrm{~min}$ in the SO group, $5.12 \pm 0.28 \mathrm{~min}$ in UO group and $6.30 \pm 0.40 \mathrm{~min}$ in UT group, with no statistical differences among them (Table 1)

Changes in percutaneous oxygen saturation, heart rate and blood pressure during gastrointestinal endoscopic procedures

Percutaneous oxygen saturation in the UT group $(-0.947 \pm 0.308 \%)$ showed a transient drop compared with SO $(0.161 \pm 0.246 \%)$ and UO $(-0.258 \pm 0.213 \%)$ groups at the beginning of the endoscopic procedure (Figure $1 \mathrm{~A})$. Heart rate rate showed no significant differences among the SO, UO and UT groups (Figure 1B). Changes in systolic blood pressure in the UO group $(-0.883 \pm 1.578 \mathrm{mmHg})$ immediately after insertion (esophagus and gastric angle to antrum) were lower compared with the SO $(6.475 \pm 2.098 \mathrm{mmHg})$ and UT groups $(4.44 \pm 2.096 \mathrm{mmHg}$ ) (Figure $1 \mathrm{C}$ ). The rate-pressure product in the 
UO group was comparable with that in the UT group during endoscopy, and the SO group showed a continuously higher level than the UO and UT groups. There was no significant difference between UO and UT groups (Figure 1D). In patients who underwent transnasal EGD (UT group), 54.4\% (31 of 57) expressed a preference for transnasal EGD for their next examination. The percentage of patients who had no preference for transnasal or transoral EGD was 8.8\% (five of 57), and who would prefer transoral EGD was $36.8 \%$ (21 of 57).

\section{DISCUSSION}

In the present study, we investigated cardiocirculatory changes and tolerance during EGD in elderly patients using three different types of endoscopy with oral or transnasal insertion. Among elderly patients, transoral thin EGD demonstrated fewer cardiocirculatory effects than transnasal EGD without sedation. Based on the questionnaire survey, the percentage of elderly patients who preferred transnasal EGD was lower than previously reported. Our results indicate that transnasal EGD is not always the safest or most tolerable procedure for elderly patients partially because of transient decreases in oxygen saturation at the time of endoscope insertion. Moreover, from a cardiocirculatory perspective, transoral thin EGD is as safe as transnasal EGD and is well tolerated by elderly patients without sedation.

In a study investigating transnasal EGD in elderly patients, Yuki et al (14) reported that unsedated transnasal EGD was safer than conventional transoral EGD in elderly patients. In that study, they defined patients $\geq 65$ years of age as elderly and used conventional transoral EGD as a control, while in our study, we defined patients $\geq 75$ years of age as elderly and used transoral thin EGD as a comparator with transnasal EGD. These differences in patients and methods may explain the difference in results between that study and ours.

Although the the prevalence of Helicobacter pylori has recently been lower in younger generations in Japan, the mortality rate of gastric cancer in the elderly generation has remained high (21). Because the mortality rate of gastric cancer remains high in elderly patients, screening EGD is essential for these patients in Japan. Although survey data from the United States suggest that $>98 \%$ of EGDs and colonoscopies are performed with sedation $(22,23)$, approximately $30 \%$ of EGD is commonly performed without sedation in Japan (24). Similarly, $>75 \%$ of EGDs are performed without sedation in many European countries (25). Thus, tolerable and safe unsedated EGD is needed for screening in elderly patients.

Before discussing calibre size and endoscope insertion method, we should consider physiological parameters in elderly patients. In general, aging is associated with significant cardiopulmonary modifications, both structural and functional. Apart from the decrease in total blood volume and the increase in total peripheral resistance, elderly individuals have altered cardiovascular homeostasis including increases in spontaneous blood pressure variability and decreases in heart rate variability (26). Pulmonary function is also affected by aging. Physiological aging of the respiratory system correlates with dilation of alveoli, enlargement of airspaces, decrease in surface exchange area and loss of supporting tissue for peripheral airways. The strength of respiratory muscle also decreases with aging; consequently, adaptability for exercise or acute disease is also reported to be diminished $(27,28)$. Endoscopy in elderly patients may be less effective given these physiological pulmonary and cardiovascular changes.

Regarding calibre size, Preiss et al (29) indicated that unsedated transoral thin EGD is well tolerated, feasible and as safe for patients as the transnasal EGD without sedation. If the use of transoral thin endoscopes (diameter $<6 \mathrm{~mm}$ ) becomes more widely adopted, the need for sedation during EGD may decrease. A multicentre randomized controlled trial in a United States population comparing unsedated endoscopy using transoral thin endoscopes with sedated endoscopy found no significant differences in physician satisfaction, technical ease of the procedure, patient satisfaction or patient willingness to repeat the procedure (30). Other studies have also reported that patients may be able to undergo transoral thin EGD without sedation $(15,16)$.

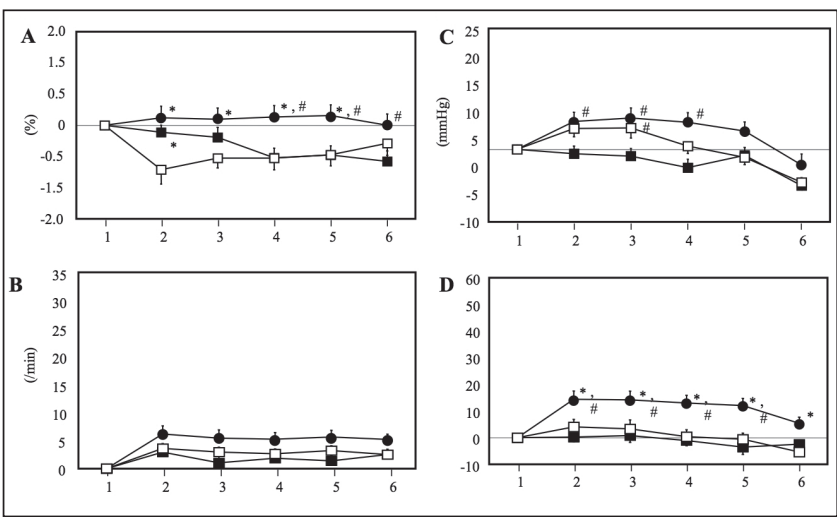

Figure 1) A Changes in percutaneous oxygen saturation during the course of esophagogastroduodenoscopy (EGD) $(* P<0.05$ compared with UT group; ${ }^{P}<0.05$ compared with SO group). B Changes in heart rate during the course of EGD $\left(* P<0.05\right.$ compared with UT group; ${ }^{*} P<0.05$ compared with UO group). C Changes in systolic blood pressure during the course of EGD $\left(* P<0.05\right.$ compared with UT group; ${ }^{P}<<0.05$ compared with UO group). D Change in rate-pressure product (pulse rate $\times$ systolic blood pressure)/100 during the course of EGD. • SO group - transoral EGD using standard endoscope; UO group - transoral EGD using thin endoscope; 口UT group - transnasal EGD using thin endoscope. 1: 2 min before examination; 2: Esophagus; 3: Gastric angle to antrum; 4: Pyloric ring to the duodenal bulb; 5: Upper gastric body; 6: Immediately after evulsion of endoscopy

Using the transnasal insertion route is also considered whenever a thin endoscope is used in the endoscopic examination. Transnasal EGD is known to induce less frequent gagging episodes, nausea, choking sensation and pharyngeal discomfort compared with transoral EGD $(7,8)$. For this reason, unsedated transnasal EGD has been reported to be safer and more tolerable than transoral EGD (31-33) in younger and older generations.

In our study, however, the advantages of transnasal EGD for elderly patients (age $\geq 75$ years) was not confirmed. Even when lower pulmonary function in elderly patients is considered, transnasal EGD may not be suitable due to its effect on pulmonary function (5).

Our results suggest that transoral thin EGD without sedation represents a safe and acceptable approach in elderly patients.

ACKNOWLEDGEMENT: This study was supported by the staff of New Ooe Hospital; Tomoko Kinugawa, Yaeno Miyakawa, Yukiko Sato, Youko Kato, Sachiko Igaki, Hiromichi Furukawa and Kazuya Itagaki. The authors greatly appreciate Prof Richard Kozarek, Virginia Mason Medical Center, USA, for his thoughtful advice to our study. This work was supported by a Grant-in-Aid for Scientific Research (B) to TY (No 21390184); a Grant-in-Aid for Challenging Exploratory Research to YN (No 08101559); a Grant-in-Aid for Young Scientists (B) to KU (No 21790688) from the Japan Society for the Promotion of Science; the City Area Program to TY and YN from the Ministry of Education, Culture, Sports, Science and Technology, Japan; and the Adaptable and Seamless Technology Transfer Program through target-driven R\&D to YN from the Japan Science and Technology Agency.

DISCLOSURES: Yoshito Itoh and Nobuaki Yagi have an affiliation with a donation-funded department from AstraZeneca Co, Ltd; Eisai Co, Ltd; Otsuka Pharmaceutical Co, Ltd; MSD KK; Dainippon Sumitomo Pharma Co, Ltd; Chugai Pharmaceutical Co, Ltd; FUJIFILM Medical Co, Ltd; and Merck Serono Co, Ltd. Yuji Naito has received scholarship funds from Otsuka Pharmaceutical Co, Ltd, and Takeda Pharmaceutical Co, Ltd. Yoshito Itoh has received scholarship funds from MSD KK and BristolMyers KK. The other authors have no financial disclosures or conflicts of interest to declare. 


\section{REFERENCES}

1. Kinoshita Y, Ishido S, Nishiyama K, et al. Arterial oxygen saturation, blood pressure, and pulse rate during upper gastrointestinal endoscopy - influence of sedation and age. J Clin Gastroenterol 1991;13:656-60.

2. Ishido S, Kinoshita Y, Kitajima N, et al. Fentanyl for sedation during upper gastrointestinal endoscopy. Gastrointest Endosc 1992;38:689-92.

3. Froehlich F, Schwizer W, Thorens J, et al. Conscious sedation for gastroscopy: Patient tolerance and cardiorespiratory parameters. Gastroenterology 1995;108:697-704.

4. Scott-Coombes DM, Thompson JN. Hypoxia during upper gastrointestinal endoscopy is caused by sedation. Endoscopy 1993;25:308-9.

5. Tatsumi Y, Harada A, Matsumoto T, et al. Feasibility and tolerance of 2-way and 4-way angulation videoscopes for unsedated patients undergoing transnasal EGD in GI cancer screening. Gastrointest Endosc 2008;67:1021-7.

6. Saeian K. Unsedated transnasal endoscopy (the Shaker technique): An alternative for assessment of supraesophageal complications of gastroesophageal reflux. Am J Med 2003;115(Suppl 3A):144S-149S.

7. Yagi J, Adachi K, Arima N, et al. A prospective randomized comparative study on the safety and tolerability of transnasal esophagogastroduodenoscopy. Endoscopy 2005;37:1226-31.

8. Campo R, Montserrat A, Brullet E. Transnasal gastroscopy compared to conventional gastroscopy: A randomized study of feasibility, safety, and tolerance. Endoscopy 1998;30:448-52.

9. Roy JF, Duforest D, Marek TA. Prospective comparison of nasal versus oral insertion of a thin video endoscope in healthy volunteers. Endoscopy 1996;28:422-4.

10. Dean R, Dua K, Massey B, et al. A comparative study of unsedated transnasal esophagogastroduodenoscopy and conventional EGD. Gastrointest Endosc 1996;44:422-4.

11. Bampton PA, Reid DP, Johnson RD, et al. A comparison of transnasal and transoral oesophagogastroduodenoscopy. J Gastroenterol Hepatol 1998;13:579-84.

12. Mulcahy HE, Riches A, Kiely M, et al. A prospective controlled trial of an ultrathin versus a conventional endoscope in unsedated upper gastrointestinal endoscopy. Endoscopy 2001;33:311-6.

13. Sivak MV Jr. The nose: Is this the route to improving esophagogastroduodenoscopy? Gastrointest Endosc 1999;49:395-8.

14. Yuki M, Amano Y, Komazawa Y, et al. Unsedated transnasal small-caliber esophagogastroduodenoscopy in elderly and bedridden patients. World J Gastroenterol 2009;15:5586-91.

15. Horiuchi A, Nakayama Y. Unsedated ultrathin EGD by using a 5.2-mm-diameter videoscope: Evaluation of acceptability and diagnostic accuracy. Gastrointest Endosc 2006;64:868-73.

16. Nelson DB, Block KP, Bosco JJ, et al. Technology status evaluation report: Ultrathin endoscopes esophagogastroduodenoscopy: March 2000. Gastrointest Endosc 2000;51:786-9.

17. World Medical Association. World Medical Association Declaration of Helsinki: Ethical Principles for Medical Research
Involving Human Subjects. Seoul: From the 59th World Medical Association Assembly, 2008. <www.wma.net/ en/30publications/10policies/b3/17c.pdf> (Accessed November 5, 2013).

18. Adachi W, Yazawa K, Owa M, et al. Quantification of cardiac stress during EGD without sedation. Gastrointest Endosc 2002;55:58-64.

19. Gobel FL, Norstrom LA, Nelson RR, et al. The rate-pressure product as an index of myocardial oxygen consumption during exercise in patients with angina pectoris. Circulation 1978;57:549-56.

20. Robinson BF. Relation of heart rate and systolic blood pressure to the onset of pain in angina pectoris. Circulation 1967;35:1073-83.

21. Bertuccio P, Chatenoud L, Levi F, et al. Recent patterns in gastric cancer: A global overview. Int J Cancer 2009;125:666-73.

22. Cohen LB, Wecsler JS, Gaetano JN, et al. Endoscopic sedation in the United States: Results from a nationwide survey. Am J Gastroenterol 2006;101:967-74.

23. Faulx AL, Vela S, Das A, et al. The changing landscape of practice patterns regarding unsedated endoscopy and propofol use: A national Web survey. Gastrointest Endosc 2005;62:9-15.

24. Junji Y, Yoshinori I, Hirotaka O, et al. The 5th national survey about procedural accidents of gastrointestinal endoscopy five years from 2003 to 2007 (in Japanese). Gastroenterological Endoscopy 2010;52:95-103.

25. Ladas SD, Aabakken L, Rey JF, et al. Use of sedation for routine diagnostic upper gastrointestinal endoscopy: A European Society of Gastrointestinal Endoscopy survey of National Endoscopy Society members. Digestion 2006;74:69-77.

26. Ferrari AU. Modifications of the cardiovascular system with aging. Am J Geriatr Cardiol 2002;11:30-3.

27. Oyarzun GM. [Pulmonary function in aging]. Rev Med Chil 2009; 137:411-8.

28. Janssens JP, Pache JC, Nicod LP. Physiological changes in respiratory function associated with ageing. Eur Respir J 1999; 13:197-205.

29. Preiss C, Charton JP, Schumacher B, et al. A randomized trial of unsedated transnasal small-caliber esophagogastroduodenoscopy (EGD) versus peroral small-caliber EGD versus conventional EGD. Endoscopy 2003;35:641-6.

30. Garcia RT, Cello JP, Nguyen MH, et al. Unsedated ultrathin EGD is well accepted when compared with conventional sedated EGD: A multicenter randomized trial. Gastroenterology 2003;125:1606-12.

31. Thota PN, Zuccaro G Jr, Vargo JJ II, et al. A randomized prospective trial comparing unsedated esophagoscopy via transnasal and transoral routes using a 4-mm video endoscope with conventional endoscopy with sedation. Endoscopy 2005;37:559-65.

32. Dumortier J, Napoleon B, Hedelius F, et al. Unsedated transnasal EGD in daily practice: Results with 1100 consecutive patients. Gastrointest Endosc 2003;57:198-204.

33. Kawai T, Miyazaki I, Yagi K, et al. Comparison of the effects on cardiopulmonary function of ultrathin transnasal versus normal diameter transoral esophagogastroduodenoscopy in Japan. Hepatogastroenterology 2007;54:770-4. 


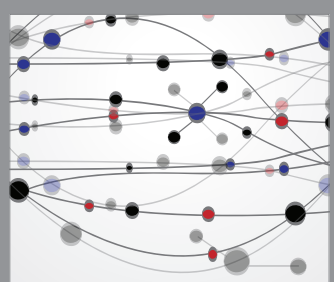

The Scientific World Journal
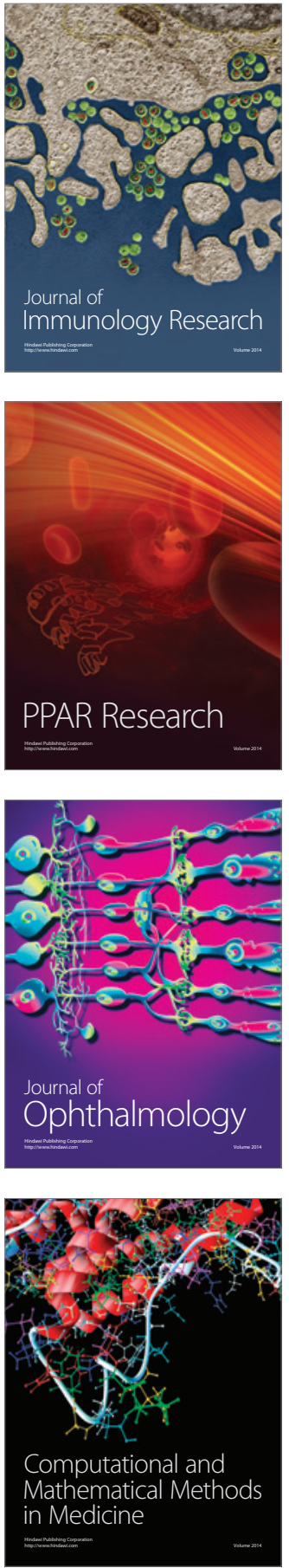

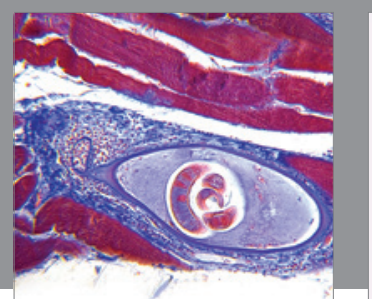

Gastroenterology Research and Practice

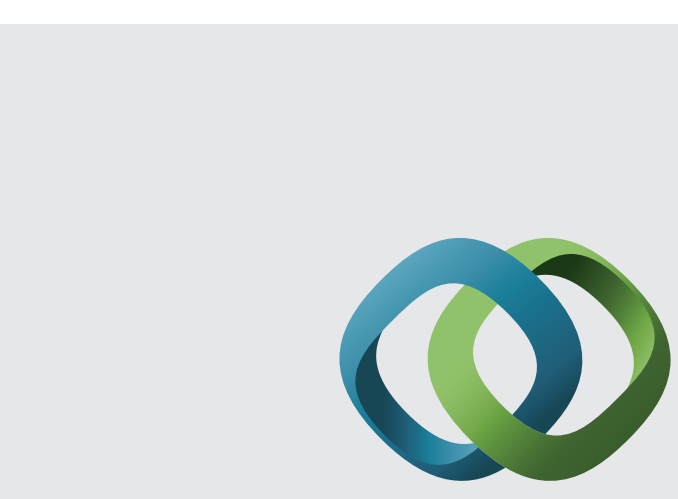

\section{Hindawi}

Submit your manuscripts at

http://www.hindawi.com
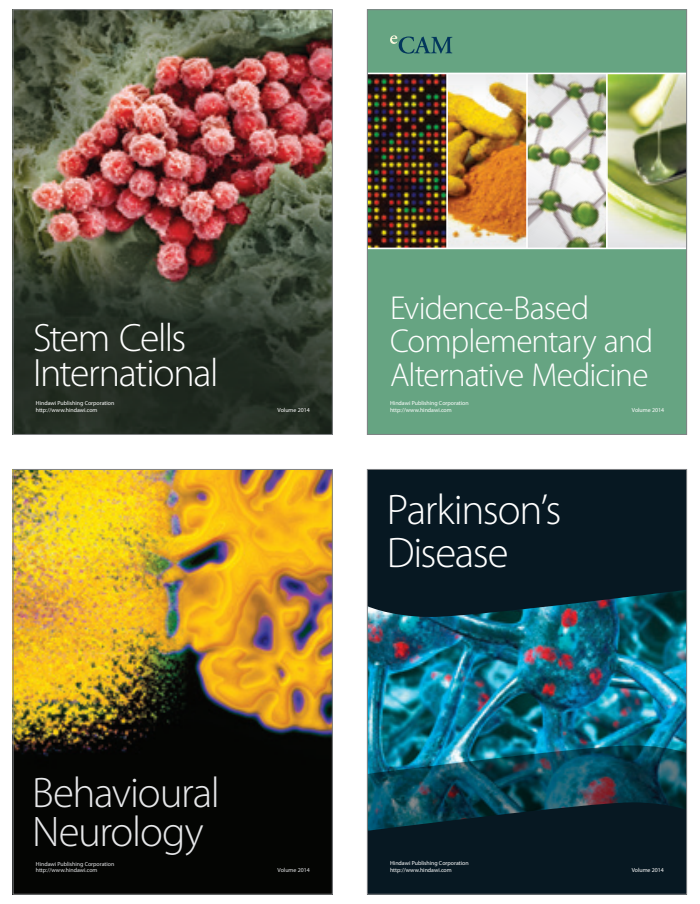
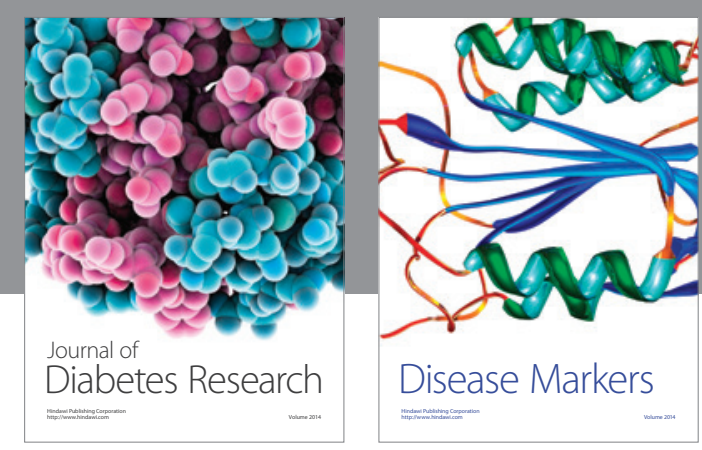

Disease Markers
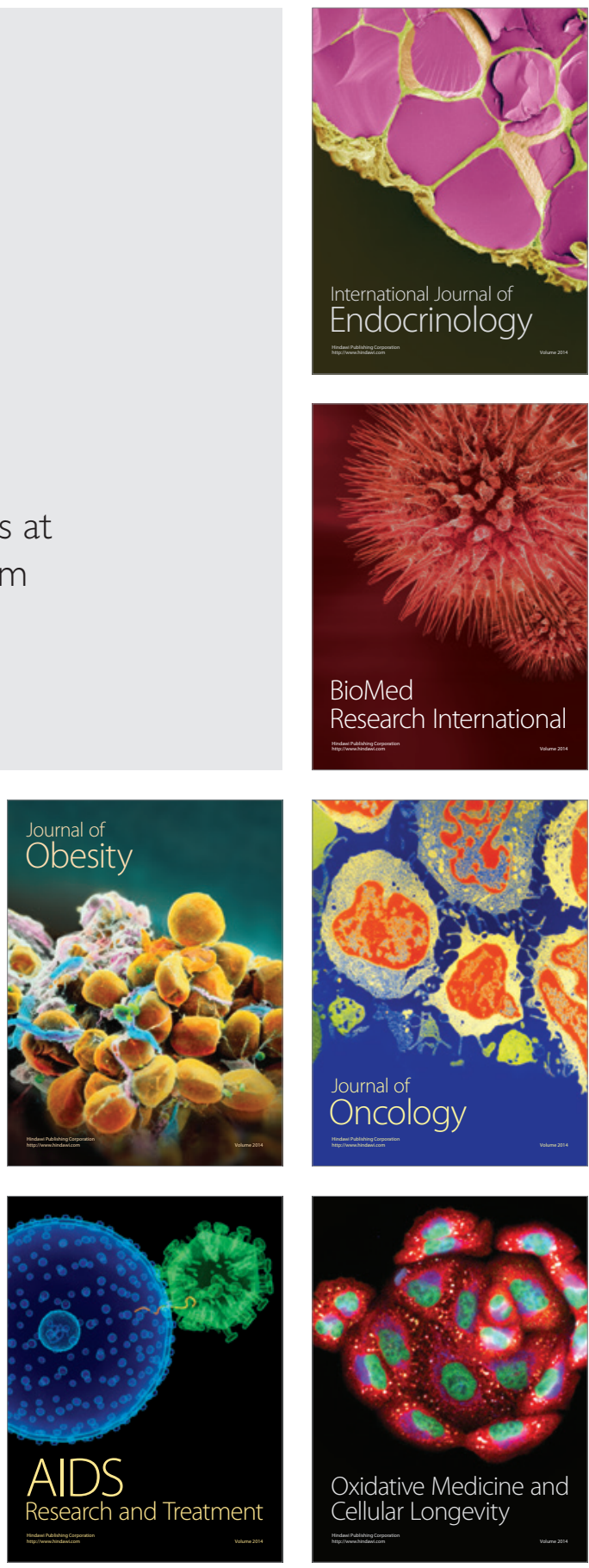